\title{
AS BASES CONCEITUAIS DOS DOCUMENTOS OFICIAIS DE ATENÇÃO À SAUDE DO ADOLESCENTE*
}

\author{
CONCEPTUAL BASES OF ADOLESCENT HEALTH CARE \\ DOCUMENTS ISSUED BY NATIONAL AND INTERNATIONAL \\ OFFICAL-ORGANIZATIONS
}

GROSSMAN, E.; CARDOSO, M. H. C. A. As Bases Conceituais dos Documentos Oficiais de Atenção à Saúde do Adolescente. Rev. Bras. Cresc. Desenv. Hum., São Paulo, 7(2), 1997.

\begin{abstract}
Resumo: Este artigo objetiva analisar as concepções incluídas nos documentos de atenção à saúde do adolescente, veiculados por órgãos gestores nacionais e internacionais, notadamente, Ministério da Saúde, Organização Mundial da Saúde e Organização Panamericana da Saúde, a respeito das definições de adolescência, de atenção à saúde do adolescente e do perfil do médico que presta assistência a esse grupo. Estes documentos foram analisados tematicamente correlacionando os tópicos acima apontados às concepções que os embasaram. A análise demonstrou que a adolescência está definida por três critérios: o cronológico ligado às transformações somáticas, o da construção de um padrão típico de adolescente e o da hegemonia do biológico numa proposta explicitada como interdisciplinar; que a atenção à saúde do adolescente exprime-se com base em uma concepção Luminista, teleológica e normativa de adolescência e, finalmente, que o papel do médico está postulado como o de dizimador de conflitos funcionando como uma espécie de pater-mater extraparental.
\end{abstract}

Palavras-chave: adolescência, atenção à saúde do adolescente, documentos oficiais.

\section{INTRODUÇÃO}

Nas últimas décadas, a população de adolescentes e jovens, no continente latinoamericano, tem experimentado um considerável aumento em relação à outros grupos etários, tanto em termos absolutos quanto relativos. Segundo dados do Anuário Estatístico do Brasil (IBGE,1992), a população de 10 a 17 anos constituia-se em 26.265.964 indivíduos, compondo aproximadamente $1 / 5$ da população brasileira.
A magnitude em termos numéricos, a importancia da saúde física e "psicossocial” para o bom desempenho do indivíduo durante esta fase e nas etapas sucessivas, a grande variedade e crescente número de circunstâncias que aumentariam o risco e os danos aos quais estariam expostos, são os argumentos utilizados nos documentos oficiais de atenção à saúde dos adolescentes para justificar o lugar de destaque conferido à sua saúde no panorama mundial, em geral, e na Região das Américas, em particular.

\footnotetext{
* Artigo baseado em pesquise desenvolvida para dissertação de mestrado apresentada à Pós-Graduação em Saúde da Criança e da Mulher do Instituto Fernandes Figueira/Fundação Oswaldo Cruz - 1995.

1 Núcleo de Estudos da Saúde do Adolescente - Universidade do Estado do Rio de Janeiro. End: Av. 28 de Setembro 109, Fundos, Pavilhão Floriano Stoffel, Rio de Janeiro - RJ, CEP: 20551-030.

2 Depto. de Ensino Instituto Fernandes Figueira - Fundação Oswaldo Cruz. End: Av. Rui Barbosa 716, 40 andar, Rio de Janeiro-RJ, CEP: 22250-020.
} 
Atualmente muito se pensa e se escreve sobre a adolescência, podendo-se afirmar que vive-se o século da adolescência. As publicações à respeito dessa temática abarcam inúmeros profissionais estudiosos dos aspectos demográficos, epidemiológicos, sociológicos, antropológicos, psicológicos, médicos, dentre outros.

A preocupação em entender o comportamento do adolescente - específico na evolução humana e produto de vivências particulares transcende o interesse científico para constituirse em estratégia política, principalmente nos países em desenvolvimento.

Os documentos oficiais de atenção à saúde dos adolescentes são fontes privilegiadas para o entendimento de como e porque a sociedade operacionaliza a saúde como instrumento de conhecimento, administração e controle do futuro. Apreender tais documentos dentro de sua moldura política é, pois, fundamental aos profissionais a quem eles se dirigem para uma reflexão acerca da adequação entre as normas preconizadas e a realidade cotidiana do exercício da profissão.

\section{ASPECTOS METODOLÓGICOS}

Foram analisados os documentos divulgados a partir de 1976 até 1994, oriundos da OMS, OPAS e do Ministério da Saúde, enfocando-se preferencialmente aqueles que versavam sobre a atenção à saúde do adolescente de uma forma geral em relação aos de cunho temático específico.

O primeiro passo foi analisar as fontes no intuito de verificar se, realmente, poderiam ser consideradas como discursos de caráter político. Para tanto aplicou-se a proposta de OSAKABE (1977), segundo a qual todo discurso político envolve uma argumentação fundamentada em três atos distintos: o de promover o ouvinte cuja participação interessa ao locutor; o de envolver o ouvinte para anular a possibilidade de crítica e, finalmente, o de engajar o ouvinte, transformando-o em sujeito das ações propostas.

Em seguida procedeu-se à análise de conteúdo propriamente dita, destacando-se as concepções e definições neles encontradas, de adolescência, de atenção à saúde do adolescente e estratégias sugeridas para a sua viabilização e do que deveria ser o perfil dos profissionais de saúde que trabalham com essa clientela.

O estudo visou decompor o conjunto dos documentos em partes, tendo em vista reconhecer a natureza particular de cada um e a relação entre eles. Este procedimento metodológico objetivou permitir a compreensão ampliada das proposições, para além de uma impressão geral e totalizante.
Por outro lado, empreendeu-se a contextualização considerando-se os emissores, os destinatários, as organizações responsáveis, as finalidades enfim, todos os procedimentos preconizados pela crítica documental interna e externa.

Enfatizou-se o que havia de comum à todos os documentos, apesar de se atentar para as suas diferenças, entendendo-se semelhanças e contrastes como parte do processo de pensar a saúde do adolescente, portanto, um processo que expressa um movimento constante, sujeito à mudanças e para o qual essa pesquisa pretende contribuir.

\section{OS DOCUMENTOS OFICIAIS E SUAS DEFINIÇÕES}

\section{Adolescência}

A definição de adolescência, presente nos documentos estudados, está concebida com base em três critérios: o aspecto cronológico articulado diretamente às transformações somáticas; a construção de um padrão típico de adolescente e a incorporação de outros ramos do conhecimento além do biológico, porém com subordinação destes à dimensão somática.

\section{O Critério Crornológico \\ Mas eu acho que se devia contar os anos pela alma. Agente dizia: aquele cara mor- reu com vinte anos de alma. E o cara ti- nha morrido mas era com setenta anos de corpo.}

Clarice Lispector.

ARIES (1981) assinalou que a sociedade ocidental tem se pautado em referências que denominou: o mundo da fantasia, simbolizado pelos nomes; o mundo da tradição, representado pelos sobrenomes e o mundo da exatidão e dos números, representado pelas idades, atributos passíveis de mensuração.

Na prática médica, não são raros os serviços de Pediatria que dividem seus setores por faixas etárias: enfermaria de lactentes, de pré-escolares e de escolares. Aqui observa-se uma fragmentação da infância em subdivisões que fazem uma associação direta e universal entre idade e atributo social, mais especificamente, o nível de escolarização. Este mundo numérico utiliza-se da estatística para enfatizar o que é comum à maioria dos seres humanos de uma determinada idade, ou pelo menos, o que deveria ser, dando ênfase à demarcação e às diferenças entre os grupos etários.

A caracterização de adolescência, presente nos documentos estudados, tem como primei- 
ro distintivo sua delimitação em limites etários precisos. O período definido como adolescência, na unanimidade desses documentos, é aquele compreendido entre os 10 e 19 anos, isto é, a segunda década da vida. A juventude é descrita como o período compreendido entre os 15 e 24 anos. A adolescência é, também, subdividida em duas fases: adolescência inicial - 10 a 14 anos - e adolescência propriamente dita ou segunda fase - 15 a 19 anos (OPAS/OMS, 1989). Alguns documentos fazem ressalvas ao critério cronológico, identificando-o como de utilidade para propostas de estandardização, mas reconhecendo-o como socialmente arbitrário (WHO, 1986).

Considerando esses limites, não como números escolhidos ao acaso, mas uma das formas de uma sociedade se descrever, de expressar sua visão de mundo e de homem, eles revelam, sobretudo, uma classificação que é fruto da valorização da aparência externa e não das realizações peculiares à cada um.

A preocupação em se encontrar um critério que contemplasse a totalidade dos adolescentes, com bases objetivas de caracterização e aferição, determinou que fosse levado em consideração o critério somático, isto é, as mudanças morfológicas e fisiológicos que constituem a puberdade. A puberdade é um fenômeno universal da espécie humana, apesar das singularidades individuais, na seqüência e intervalos, no aparecimento dos eventos puberais. Nesse sentido, o intervalo etário definido como adolescência articula-se diretamente ao processo de desenvolvimento biológico.

Os documentos estudados enfatizam que, além das transformações anátomo-fisiológicas, a adolescência é um período de transição da infância à idade adulta, pleno de transformações psicológicas em que o sujeito está em busca de uma identidade madura e é movido por uma atitude social reinvindicatória. Porém, fica claro perceber que essas não são vivências circunscritas à um período de tempo previamente estabelecido.

Todavia, o que realmente chama a atenção é o fato da adolescência ter sido exclusivamente definida e alicerçada no que pode ser formulado em linguagem matemática: os estirões no crescimento e a modificação da forma do corpo; o crescimento e desenvolvimento das gônadas; o desenvolvimento dos órgãos sexuais secundários e das características sexuais; as modificações na composição do corpo e o desenvolvimento dos sistemas respiratório, circulatório e muscular.

\section{Padrão Tipico de Adolescente \\ A arquitetura é infinitamente variada a partir de alguns materiais de base. A com-}

\section{binação hábil de um número restrito de elementos pode resultar numa imensa di- versidade.}

Jean Hamburger

Embora a maioria dos documentos destaque a importância de ser levado em consideração o processo histórico da adolescência, ao discutir a saúde do adolescente e as características dos serviços e práticas a eles destinadas, refere-se à um padrão típico de adolescente, que apresenta uma uniformidade nas suas condições de existência que, por sua vez, demanda intervenções passíveis de normalização. Tal concepção supõe a existência de um padrão médio, característico do adolescente normal, cuja classificação em normal ou patológico está na dependência da menor ou maior proximidade a este padrão de referência. Isto é flagrante na expressão síndrome da adolescência normal (KNOBEL, 1988), utilizada em relação ao desenvolvimento psicológico do adolescente, de maneira a traduzir a existência de modalidades de conduta e comportamento, essencialmente as mesmas para a totalidade dos adolescentes. A síndrome da adolescência normal apresenta-se com as seguintes características: busca de si mesmo e da identidade adulta; tendência grupal; necessidade de intelectualizar e fantasiar; crises religiosas; deslocação temporal; evolução sexual desde o auto-erotismo até a hetero sexualidade; atitude social reinvindicatória; contradições sucessivas em todas as manifestações da conduta; separação progressiva dos pais e constantes flutuações do humor e do estado de ânimo.

Porém, o comportamento, as idéias e os atos de um indivíduo sempre refletem a forma particular pela qual ele tomou consciência de seu momento histórico, o que altera, a cada momento, as condições de espaço e tempo humanos. A descrição de tal "fenômeno sindrômico" nega o fato do homem assumir uma forma própria de ser em cada tempo e lugar históricos, restringindo suas características a um mero desenvolvimento cronológico.

As definições de adolescência, presentes nos documentos avaliados, são considerações homogeneizantes, minimizando a diversidade de formas que o adolescente ou grupos de adolescentes possam adorar no cotidiano de suas vidas inseridas na coletividade. As tradições, os costumes, os ritos não são salvaguardados, sendo pelo contrário, nivelados e uniformizados. Os documentos, portanto, traduzem uma concepção pragmática e empiricista da história, alienada da temporalidade/espacialidade humana que, neles, se transforma em um substrato passível de previsibilidade e controle. 
A partir da mortalidade, do tempo e do espaço é que levantamos a questão "de onde viemos, o que somos e para onde vamos?” e aí se expressa a historicidade do gênero humano, com a qual a historicidade de cada ser esteve e estará sempre correlacionada (HELLER, 1993). As definições de adolescência contempladas nos documentos oficiais estão isentas de historicidade, por não conceberem que os homens são tempo e espaço humanos, distanciando a história da vivência terrena e de sua finalidade como via de conhecimento da situação humana.

\section{Incorporacão de Outros Ramos do Saber - A Hegemonia do Biológico \\ Penso que é tão maravilhoso o que me acontece. Não só o que aparece no corpo mas o que se realiza por dentro. \\ Anne Frank}

São unânimes as referências às transformações físicas, psicológicas e sociais que ocorrem no período da adolescência. É empregada, de forma repetida, a expressão transição biopsicossocial para caracterizar essa fase evolutiva do ser humano. Ao mesmo tempo que os documentos delimitam a adolescência cronologicamente. apontam-na como determinante de situações comportamentais passíveis de implicar no adoecimento, subordinando-as a um intervalo temporal previamente estabelecido.

Apesar da ênfase na importância de uma equipe multiprofissional para o manejo adequado das questões dessa clientela, são as transformações somáticas que delimitam, concretamente, o período designado como adolescência. E em torno do caráter biológico que se organiza a apreensão dos demais, isto é, só a partir das transformações do corpo que se pauta a necessidade de se preocupar com as demais condições ligadas à adolescência.

A idéia de subordinação é reforçada pela utilização prioritária dos indicadores de saúde, desenhados a partir de uma ética biológica para o diagnóstico da problemática e principais necessidades de saúde do adolescente, tais como: as medidas antropométricas, o estado nutricional, a morbidade e a mortalidade nessa faixa etária.

\section{ATENÇÃO À SAUDE DO ADOLESCENTE}

A saúde e o bem-estar do adolescente são caracterizados, nos documentos analisados, como o produto de interrelações dos três sistemas básicos: biológico, psíquico e social. A atenção à saúde preconizada para esse grupo, ressalta a impor- tância de ser levada em consideração à natureza múltipla de sua problemática. Isto determina a recomendação de um conjunto de ações que enfatizem tanto os aspectos fisiopatológicos como os psicossociais (OPAS/OMS, 1990; MADDALENO, 1988). A incorporação do conceito de saúde integral dentro de um continuem e vinculada aos aspectos de "bem-estar e desenvolvimento", facilitaria o êxito dos processos de "socialização, espiritualidade, desenvolvimento integral e ótimo desempenho" durante e após o período da adolescência. As prioridades de saúde do adolescente são, então, descritas como todas as medidas de prevenção dos problemas ligados ao processo reprodutivos; aos acidentes e à violência; ao uso e abuso de fumo, álcool, drogas e inalantes, bem como, às questões de saúde mental. Essa priorização pretende conduzir a um enfoque preventivo, “ prático e eficaz” (OPAS/ OMS,1989; MADDALENO,1988).

A definição de atenção à saúde do adolescente expressa quatro fundamentos embasadores: uma concepção Luminista, uma argumentação teleológica, a adoção de pressupostos normativos e um discurso interdisciplinar não igualitário.

\section{Concepção Iluminista}

É aqui o segundo nascimento de que falei; é aqui que o homem nasce verdadeiramente para a vida (...). Esta época, quando acabam as educações comuns, é exatamente a época em que a nossa deve começar...

Jean-Jacques Rousseau

O Iluminismo pode ser definido como um movimento de idéias, uma forma de pensar, com origem no século XVII, porém somente consolidado no século XVIII. Seu programa era a difusão do uso da razão para dirigir o progresso da vida em todos os seus aspectos. Concebia a razão como fonte de verdades indiscutíveis ou generalizações legitimadas por uma validade metodológica. Desta forma, propunha a utilização de métodos analíticos racionais: comparações e sínteses, através de procedimentos indutivos e dedutivos, preconizando a construção de um corpo de leis universais e imutáveis (TESTONI,1984; FERREIRA,1993).

Os documentos de atenção à saúde do adolescente analisados recomendam a aplicação de "enfoques integradores tais como o conceito de risco" entendendo-se assim, que aquilo que determina a saúde de um adolescente é o seu nível de exposição a um ou mais "fatores de risco". A assistência ao adolescente, dessa forma, é operacionalizada através da "supressão ou com- 
pensação" desses fatores, para diminuir as probabilidades de dano a ele e à sociedade (OPAS/ OMS,1990). Se um fato é considerado de risco para um adolescente, indutivamente, ele se transforma em risco para todos os demais. De forma análoga à filosofia iluminista, isto traduz uma atitude pragmática de racionalização da historicida de, em prol de uma vivência socialmente mais produtiva, através da construção de instrumentos conceituais operativos.

Locke, em sua obra Da Educação das crianças, chama a atenção dos pais para as virtudes da prevenção como o meio mais eficaz de preservar a saúde dos filhos: "Falando aqui da saúde, meu objetivo não é dizer-vos como um médico deve tratar uma criança enferma ou valetudinária, mas apenas indicar o que os pais devem fazer, sem o recurso da medicina, para conservar e aumentar a saúde de seus filhos ou pelo menos para dar-lhes uma constituição que não esteja sujeita a doenças” (apud GÉLIS,1993 p. 316).

Na totalidade do material investigado, observa-se a ênfase dada aos aspectos preventivos ou protetores, no cuidado do adolescente, com a finalidade de formação de adolescentes física e moralmente sádios, transformando suas vidas em produtivas para toda a sociedade. Essa moral utilitarista pode ser identificada nas palavras do então diretor geral da Organização Mundial da Saúde, H. Nakajima, em um de seus pronunciamentos: "Se se ajuda os jovens a ter relações positivas e saudáveis, a desenvolver-se como indivíduos antes de casar-se e de ter filhos, a exercitar suas mentes e corpos de forma saudável - se comem bem e permanecem livres de tabaco, do álcool e outras drogas, livres dos riscos de uma gravidez e paternidade precoces e livres da infecção, se praticam a higiene e são capazes de experimentar e explorar seu mundo sem risco excessivo de lesão e com oportunidades para solidarizar-se com outros, suas vidas serão ricas e produtivas e todos se beneficiarão” (OPAS/OMS, 1989).

Para Locke, a adolescência era encarada como o estágio final do desenvolvimento humano, quando o indivíduo adquire o pensamento abstrato e a racionalidade, tornando-se autodirecionado e completo em sua identidade (VIOLATO, op. cit.). Nas fontes estudadas, a adolescência é descrita como um período de vulnerabilidade especial:” a adolescência ocupa um lugar estratégico na vida - não é demasiado cedo para adotar uma atitude responsável, nem é demasiado tarde para superar a maioria das dificuldades anteriores” (OMS, 1977 p. 32).

Rousseau manifesta que os indivíduos nascem sensíveis e são afetados pelas coisas que os cercam. Graças aos seus sentidos, aproximam-se do que lhes dá prazer e afastam-se do que os desagrada. No entanto, acredita que esses atos não são mecânicos, são fruto da educação, fator fundamental no desenvolvimento da sensibilidade e na percepção da estética dc mundo. A moral e os costumes são primordiais para o aperfeiçoamento do homem e da sociedade, portanto, prevalecem as verdades práticas de onde derivam os aspectos normativos (FERREIRA, op. cit.). Rousseau propôs quatro estágios do desenvolvimento humano que culminariam durante o período da adolescência - 15 a 20 anos -, quando o indivíduo se deslocaria de motivações egoístas para preocupações sociais e desenvolveria uma identidade. Rousseau considerava a adolescência como um segundo nascimento (VIOLATO, op. cit.).

A valorização das práticas educativas na atenção ao adolescente, especialmente aquelas relacionadas com a saúde reprodutiva, partem de uma concepção de mundo que acredita que a informação seria o principal instrumento propiciador de mudanças de comportamento. De forma análoga ao pensamento de Rousseau, esse pressuposto evidencia uma mentalidade que comprova que as possibilidades de aperfeiçoamento do ser humano seriam alcançadas através do conhecimento da natureza, neste caso, especificamente da natureza do corpo biológico.

$\mathrm{O}$ aspecto prioritariamente normativo da atenção à saúde do adolescente pode ser identificado nos diversos manuais distribuídos que visam orientar e dar suporte técnico às decisões a serem tomadas junto ao adolescente, definindo, justificando e selecionando tecnologias, padronizando procedimentos e normatizando condutas (MS, 1993).

Em síntese, de forma análoga à Filosofia das Luzes, os documentos de atenção à saúde do adolescente têm como base de suas propostas e considerações a crença na condição de que, através da Razão, estar-se-ia no caminho de transformar o adolescente em um homem completo, apto a contribuir para o presente e para o futuro dos países e do mundo em geral.

\section{AArgumentação Teleológica}

Terá número, barra e borra de carimbo? Afinal ele é gente ou registro pungente? Carlos Drummond de Andrade

Nos documentos revisados, a adolescência é entendida como um status próprio de um segmento etário da existência humana, conforme ressaltado anteriormente. Os adolescentes enfrentam determinadas situações pelo fato de serem adolescentes, o que explicaria o seu comporta- 
mento. Esse comportamento demandaria, por sua vez, intervenções específicas emrelação à saúde, pois os adolescentes, por si próprios, possuem a característica natural da vulnerabilidade. Essa fase é vista como um conjunto de situações previsíveis, algumas delas de risco para a saúde, passíveis de controle, pois sem este, o desfecho dessa fase poderia ser danoso ao próprio adolescente e à ordem socialmente instituida.

Os determinantes das necessidades de saúde do adolescente são encontrados mediante o estabelecimento de uma cultura adolescente, incitadora de seu comportamento, estático, atemporal e dotado de uma finalidade em si mesmo.

A teleologia, do grego legos $=$ final e logos = razão, explica os acontecimentos, os fatos, os eventos, os fenômenos do universo, sempre referidos a algum propósito e/ou como dotados de uma finalidade causal inexorável. A conduta humana obedeceria a um fim para o qual existe ou foi produzida. A mais célebre definição de teleologia foi a pensada por Aristóteles, no conjunto de suas obras - Politica; Da Geração dos Animais e de Anima, dentre outras - onde propõe que uma explicação completa de qualquer coisa deve levar em consideração não somente o material que a constitui, sua forma, suas causas eficientes e perceptíveis, mas também sua razão final, o propósito pelo qual ela existe e foi criada, por algo que a transcende.

A explicação do nexo final é, então, inteiramente diferente da interpretação. Esta operação responde a contingências do pensamento humano que buscaiia, ante o universo complexo, simplificá-lo para melhor atingí-lo em toda sua almejada realidade. $\mathrm{O}$ aprisionamento da adolescência em um modelo aliado à idéia de finalidade - ser adolescente $=$ comportamento de risco - postula um telos que culminaria agindo no sentido de a todos homogeneizar e historicamente almejando repetir ad-infinutum as características observáve0is.

Toda a adolescência é explicada, nos documentos estudados, por uma teleologia universal, ou seja, pressupõe-se que a maneira de viver do jovem acontece como resposta aos desígnios de uma razão: o propósito da sua própria natureza, transcendental a ele mesmo. Tal concepção pode ajudar ao conhecimento acerca das especificidades desta etapa do crescimento e desenvolvimento humano, por exemplo, como guia de questionamento para a construção de um desenho epidemiológico, mas jamais enquanto definidora de verdades embasadoras de ações de saúde.

Isso é patente no discurso relacionado ao uso de drogas, aos acidentes automobilísticos e à prática sexual. As prioridades de saúde dos adolescentes, delimitadas para a Região das Américas, estão definidas como todas as medidas de prevenção da problemática ligada ao processo reprodutivo - gravidez precoce e doenças de transmissão sexual, os acidentes e a violência, o uso e abuso de fumo, álcool, drogas e inalantes, assim como os problemas de saúde mental (OPAS/OMS, 1989). Os adolescentes são, dessa forma, encarados como objetos à mercê e à serviço da violência e dos maus costumes, passíveis de mergulhar no abismo das drogas, dos comportamentos perigosos e nas reações sexuais irresponsáveis apenas pelo falo de serem adolescentes.

E como se, com a necessidade de integrarem-se à sociedade, os adolescentes pudessem aprimorar suas qualidades ou perdê-las, pois teriam a liberdade para tanto, só que essa escolha se daria dentro de um jogo cujos dados já teriam sido lançados. Os princípios normativos, por sua vez, cumpririam a tarefa de garantir que esse jogo não se tornasse viciado.

\section{Pressupostos Normativos \\ Então o homem jovem que é honrado aprende a conhecer a moralidade hipócri- ta que Ihe foi inventada para impedir a ple- na eclosão de suas propensões físicas.}

Pablo Neruda

A preocupação presente na totalidade dos documentos estudados é a de prevenir, corrigir e controlar problemas ou desajustes. A implantação e implementação de ações dirigidas à atenção à saúde do adolescente são norteadas por discursos oficiais normativos, que se estendem desde a adequação do espaço físico e instrumental até o desenvolvimento de programas específicos com atividades pré-estabelecidas.

As normas, baseadas em generalizações, constituem-se em princípios orientadores, mas não possuem, por si próprias, valor explicativo. Assim sendo, os fenômenos são encarados como exatamente iguais não importando sua historicidade. Ou seja, o diagnóstico é feito por analogia e conseqüentemente generalizante, distanciado do fato de que os “objetos” em questão são humanos: os adolescentes.

Cabe sublinhar que os princípios organizacionais, normativos, totalizantes, são gerados em determinada visão de mundo, em uma teorização não aplicada. Esta teorização, abstrata, forneceria elementos normativos que teriam como utilidade oferecer definições iluminadoras para as teorias aplicadas. Essas, por sua vez, possuiriam uma diversidade e singularidade não passíveis de repetição. 
Os princípios normativos de atenção à saúde do adolescente deveriam possuir o caráter de uma teorização aplicada, mas, o que se nota, é que no seu posicionamento, teriam, de falo, o cunho de uma teoria elevada, perdendo, por conseguinte, a característica da complexidade de seu objeto, apesar de discursivamente a reconhecerem.

Há que se refletir a respeito da necessidade de uma teorização aplicada na abordagem da saúde do adolescente, porque tal como na historiografia, como se prova na leitura até de historiadores marxistas como Thompson ou Hobsbawn, a busca por significado só se dá na teoria aplicada (HELLER, op. cit.).

Como todas as visões de mundo implicam num conjunto de valores, vale a pena apontar que os princípios normativos aqui tratados estão impregnados dos valores daqueles que os construíram, mas desconsideram as diversidades sócio-culturais regionais de um continente habitado por uma população de origens e tradições heterogêneas.

Cita-se como exemplo a abordagem do desenvolvimento psicológico do adolescente em documento emitido pelo Ministério da Saúde, mais especificamente pelo Serviço de Assistência à Saúde do Adolescente. Neste manual há um quadro intitulado Condutas de risco do adolescente, cujo conteúdo indica: "Condutas de risco do adolescente: uso e abuso de fumo, álcool e drogas; acidentes de trânsito: dirigir em excesso de velocidade sob o uso de álcool e drogas, apostas de corridas (carro ou moto) e atividade sexual: risco de gravidez e de doenças sexualmente transmissíveis” (MS, 1993 p. 39) e fechando o quadro é enfatizado: "Referir para profissionais de saúde mental" (idem, ibidem).

Este quadro revela a tendência à previsibilidade de situações-problema dos adolescentes, propondo como abordagem das mesmas, a padronização de procedimentos, orientações e encaminhamentos rigidos e universalizantes.

\section{Discurso Interdisciplinar Não Igualitário Esse vazio que descobrimos certo dia na adolescência, coisa alguma é capaz de fazê-lo não ter ocorrido. \\ Marguerite Duras}

O modelo predominante na organização dos serviços de saúde é o assistencial, clinicamente orientado, desenhado com base na epidemiologia clássica, no qual o paradigma do biológico encontra-se em primeiro plano. Ele está firmado na abordagem cartesiana, mantendo, ainda, a separação mente-corpo.

Esse modelo pode ser evidenciado no documento emitido pelo Ministério da Saúde, em
1993, intitulado Normas de Atenção Integral à Saúde do Adolescente: "Como os fenômenos biológicos são mais fáceis de precisar e avaliar, inclusive quantitativamente, o acompanhamento do crescimento e desenvolvimento foi escolhido como a ação básica do atendimento à saúde do adolescente, entre as diversas ações prioritárias do Programa Saúde do Adolescente (PROSAD), permeando e articulando as demais ações” (p. 18).

A racionalidade do sistema existente, ainda leva cada disciplina a se levantar em Bastilha a fim de assegurar a preservação de seu território e a manutenção de seus meios. O discurso interdisciplinar não igualitário tem, por conseguinte, suas origens na crença dos médicos de que só eles estariam qualificados para determinar o que se constitui em doença, selecionando as terapias apropriadas. Essa crença os mantêm no topo da hierarquia do poder no sistema de assistência à saúde, criando obstáculos à real atenção interdisciplinar à saúde do adolescente. Por outro lado, as outras disciplinas, se utilizam, muitas vezes, de sistemas conceituais que lhes são próprios relacionados às suas lógicas, em alguns casos incompreensíveis para o restante da equipe.

A simples justaposição de saberes não leva à interação proposta e desejada, pelo contrário, enfatiza as diferenças epistemológicos de cada disciplina, contribuindo muito pouco para o esclarecimento das questões em pauta, no caso, a "problemática” do adolescente.

Ao contrário de ser concebida como uma estratégia, a interdisciplinaridade é pautada como um objeto em si, uma teoria, perdendo seu significado de desafio à articulação de diversas disciplinas entre si, por ocasião de um trabalho sobre o mesmo objeto, o que constitui um importante vetor de questionamento.

\section{PAPEL DO PROFISSIONAL DE SAÚDE NOS SERVIÇOS DE ATENÇÃO AO ADOLESCENTE}

\section{Nós transformamos os médicos em heróis, porém temos sentimentos ambíguos em relação a eles.}

Roy Porter

Parece haver uma orientação no sentido do profissional de saúde ser um dizimador de conflitos. Isto pode ser verificado neste fragmento: "Um médico que atende adolescentes deverá ser capaz de diagnosticar e tratar doenças físicas, detectar condutas desadaptativas, estar alerta a potênciais falhas no rendimento escolar, fomentar o desenvolvimento de estilos de vida saudáveis, ensinar 
educação sexual e realizar aconselhamento familiar. Deverá compreender as transformações da adolescência e outorgar um nexo vital entre o adolescente e sua família, o que manterá as relações harmônicas.” (MADDALENO, 1988 p. 136).

Além disso, fica clara, a disposição de que o médico que atende adolescentes tem como função primordial, a de ser um guia, nos moldes de um pater/mater extraparental. Seria como fazer do conhecimento, o caminho de busca da onipotência. Dessa forma, a família estaria destituída de seu papel nuclear, descartada de sua função de iniciadora e estimuladora do conhecimento, em nome da ilusão do saber científico como sinônimo de poder, garantia e controle educacional. "Se deve assumir o papel de um adulto crítico extra-parental que ajude ao adolescente a avaliar os prós e contras de uma conduta que afeta a saúde”. (Idem p. 13 7). Subsidiados pela técnica, os médicos teriam importância crucial na determinação daquilo que seria bom ou ruim para a saúde, e por que não dizer, para a vida de seus pacientes.

\section{CONSIDERAÇÕES FINAIS}

Não se pretendeu oferecer respostas prontas às questões levantadas, mas apenas evidenciar a complexidade da temática abordada e a urgente exigência de pensar novos paradigmas para a atenção à saúde do adolescente.

É fundamental a importância do conhecimento das modificações biológicas que ocorrem nos adolescentes e dos fenómenos a elas correlacionados, justificando o acompanhamento do crescimento e desenvolvimento desse grupo como ação prioritária a ser desenvolvida nos serviços de saúde.

O critério cronológico de definição de adolescência tem a finalidade de permitir uma divisão administrativa e operacional nos serviços, embora o reconhecimento da diferença entre puberdade e adolescência não deva ser ignorado. A visão da adolescência, descolada de sua historicidade, constitui-se em estratégia pouco proveitosa no objetivo de implementar ações direcionadas às reais necessidades dos indivíduos na área da saúde.
A construção de um padrão típico nega a complexidade das vivências da adolescência em função de seu enquadramento em modelos préestabelecidos.

A concepção Luminista que embasa os documentos oficiais de atenção à saúde do adolescente, transmuta-os em protagonistas da esperança no futuro ou em agentes do progresso, fazendo recair em seus ombros a tarefa de apagar o que de ruim houve no passado e o que de errado existe no presente.

A obediência cega aos pressuposto normativos, sem uma visão crítica em relação, sua adaptabilidade a um contexto específico e historicamente determinado, alicerçada em concepções teleológicas, enseja a elaboração de programas e ações fragmentadas, portanto, de eficácia real questionável.

É indiscutível a importância de uma abordagem interdisciplinar para um melhor encaminhamento das múltiplas questões trazidas pelos adolescentes e suas famílias aos serviços de saúde. Por outro lado, têm-se absoluta convicção que o setor saúde e seus representantes não têm como atribuição a solução de todos os problemas desse grupo. A interdisciplinaridade não pode ser interpretada como um objeto em si, uma teoria, e sim, como uma estratégia de trabalho.

No que diz respeito ao médico, especialmente, faz-se preciso aprimorar seu conhecimento clínico e sua escuta como fundamentais ao exercício profissional, não cabendo-lhe, de forma alguma, exercer a função a ser desempenhada pela família. Ele não é um padre, um juiz, um herói um redentor, um modelo de bom comportamen to... ele é apenas mais um ser humano cuja for mação incutiu-lhe a vontade de prevenir e curar e, quando isto não for possível, estar disponível e oferecer terapêuticas capazes de contribuir para uma melhor qualidade de vida a seus pacientes.

A adolescência não pode ser transformada em leis, ao preço de um encaixotamento de suas melodias e seus balés de essências. Assim como no mito de Eros e Psiquê, não devemos corporificar Afrodites, impondo tarefas e obstáculos a serem cumpridos e superados pelos adolescentes, em sua trajetória para à adultice, bem como pelos profissionais interessados em assistilos nos serviços de saúde. 


\begin{abstract}
This article aims to analyze concepts embodied in adolescent health care documents issued by national and international official organizations such as Ministério da Saúde (MS), World Health Organization ( $\mathrm{W}^{\wedge} \mathrm{HO}$ ) and Pan American Health Organization ( $\left.\mathrm{P}^{\wedge} \mathrm{AHO}\right)$, seeking to find out their definition of adolescence, adolescent health care and the attributes doctors must have to offer an efficient medical assistance to youth. These documents were subjected to a thematic analysis correlating the above-mentioned themes with the conceptions they are based upon. This analysis showed that, in the documents, adolescence is defined by three criterions: the chronological one attached to somatic transformations, the construction of a typical adolescent model and the prevalence of the biological approach within a interdisciplinary proposal; that adolescent health care expresses itself based upon an enlightened, teleological and normative conception of adolescence and, finally, that in order to offer an efficient medical assistance the health professional, mainly the doctor, must function like a family peacemaker and a kind of patter-mater extra parenthood.
\end{abstract}

Key-words: adolescence, adolescent health care, official documents.

\section{REFERENCIAS BIBLIOGRAFICAS}

ARIÉS, P. História social da criança e da família. Rio de Janeiro, EditoraGuanabara,1981.

FERREIRA, N., T. Cidadania: uma questão para a educação. Rio de Janeiro, Nova Fronteira, 1993.

GÉLIS, J. A Individualização da Criança In: ARIÉS, P.\& DUBY, G. (orgs.) História da Vida Privada. São Paulo, Companhia das Letras, 1993.

HELLER, A. A teoria da História. Rio de Janeiro, Ed. Civilização Brasileira, 1993.

INSTITUTO BRASILEIRO DE GEOGRAFIA E ESTATÍSTICA. BRASIL Anuário estatístico do Brasil. Rio de Janeiro, 1992.

KNOBEL, M. Desenvolvimento Psicológico In: Adolescência e Saúde. São Paulo - Secretaria de Estado da Saúde de São Paulo, Paris Editorial, 1988.

MADDALENO, M. Enfoque familiar y los problemas de salud del adolescente. In: Bibliografia número 2 - Adolescência. Brasil,OPAS/ OMS, 1988.

MINISTÉRIO DA SAÚDE. BRASIL Normas de Atenção à Saúde Integral do Adolescente. Brasília, MS - SAS,1993.

NAKAJIMA, H. Opening Address by the Director General of the WHO. In: Discusiones Técni- cas sobre la Salud de los Jóvenes. Genebra, OMS, 1989.

OMS. Necesidades de Salud de los Adolescentes. Informe de un comité de expertos de la OMS. Genebra, Série de Informes técnicos n 609,1977.

OPAS/OMS. Salud dei Adolescente. Prioridades y Estrategias Nacionales y Regionales. Washington, Boletin de la Oficina Panamericana 107 (1),1989.

OPAS/OMS. O Marco Conceitual da Saúde Integral do Adolescente e de seu cuidado. Washington, OPAS/OMS, 1990.

OSAKABE, H. A Argumentação no discurso político. Cadernos de literatura e ensaio, (2), 1977.

TESTONE, S. Iluminismo. In: BOBBIO, N. \& MATTEUCCI, N. Diccionario de politica. Madrid, Siglo Veinteuno Editores, 1984.

VIOLATO, C. History of Adolescence In: FRIEDMAN, S.B. (ed.). Comprehensive Adolescent Health Care. St. Louis, Ouality Medical Publishing, 1992, p. 3-6.

WHO. Young peoples health - a challenge for society.Genebra, Report of a WHO Study Group on Young People and "Health for All by the Year 2000" - Technical Report Series 731,1986. 